\title{
EDITORIAL
}

\section{Grandparenthood in Europe}

\author{
Karen Glaser ${ }^{1} \cdot$ Karsten Hank ${ }^{2}$ (D)
}

Published online: 15 May 2018

c) Springer-Verlag GmbH Germany, part of Springer Nature 2018

In ageing societies, family relationships across more than two generations are becoming increasingly important. A core argument on which this proposition is based refers to changes driven by sustained low fertility and increasing life expectancy, resulting in an age structure of families that has been described as a 'beanpole' rather than a 'pyramid': "a family structure in which the shape is long and thin, with more family generations alive but with fewer members in each generation" (Bengtson 2001: 5). Arguably, the claim that extended intergenerational kin relations-especially such including grandparents-have quantitatively and qualitatively gained in importance has intensified family researchers' longstanding interest in grandparenthood and grandparenting.

The extent to which grandparents play an active role in multigenerational family relations depends on several demographic factors, particularly the timing of fertility and mortality. Recent evidence from Europe and North America shows that the length of an individual's life as a grandparent varies considerably across countries and is largely influenced by cross-national differences in the timing of childbearing (Leopold and Skopek 2015). Delays in the transition to parenthood might even reduce the number of years grandparents spend living with their grandchildren, despite continuous improvements in survival at older ages (Margolis 2016). However, recent research has also noted an increase in the period of healthy grandparenthood, which may offset delays in the transition to grandparenthood due to delayed childbearing (Margolis and Wright 2017).

Next to providing detailed demographic accounts of contemporary grandparenthood, recent research has focused on the perception of the grandparental role among older adults

Responsible editor: Marja J. Aartsen

Karsten Hank

hank@wiso.uni-koeln.de

King's College London, London, UK

University of Cologne, Cologne, Germany as well as on the contribution of grandparents to family life (see Hank et al. 2018, in this issue). The enormous attention currently paid to these issues also seems to be driven by a more general — public and academic — interest in the issue of active and productive ageing (e.g. Börsch-Supan et al. 2013). Considering its considerable (economic and non-economic) societal value, it is indeed important to include productive ageing activities within families (such as the provision of childcare) in assessments of older people's active engagement in society, which often tends to be limited to 'public' activities (e.g. volunteering; Hank and Erlinghagen 2010). And if grandparents' engagement is considered as something that is relevant not only for the family but for society as a whole, we also need to reflect more upon its embeddedness in specific welfare state arrangements (e.g. Bordone et al. 2017).

Finally, understanding the role of grandparents in supporting and maintaining families is critical given changing policy environments-and changes to pension and retirement policies in particular-and for understanding inequalities in health and well-being across the life course. Rising longevity and increasing numbers of older people have led to the extension of default and state retirement ages in many countries with older people expected to participate in paid work for longer, and at the same time, to undertake critical roles in caring for children and adults. Yet, we have little understanding of how engagement in paid work at older ages may affect caregiving (and other) activities including grandchild care (e.g. Lumsdaine and Vermeer 2015). In addition, responses to the current international financial crisis such as austerity measures and cuts to public services are likely to lead to the greater expectation that grandparents will step into fill the care gap. This has raised concerns that it may be those with the fewest resources who will be increasingly likely to rely on family assistance, a response which is likely to have important implications for inequalities in later life health and well-being.

The focus of the five contributions to this Special Section of the European Journal of Ageing is on grandparenthood in the context of European welfare states (and on the Italian 
case in particular). ${ }^{1}$ To begin with, Hank et al. (2018, in this issue) aim to take stock of the insights current quantitative data sources provide on grandparenthood today. Whereas their substantive and methodological review relies heavily on European datasets-such as the Survey of Health, Ageing and Retirement in Europe, the English Longitudinal Study of Ageing, and the Generations and Gender Surveys-it also covers the US Health and Retirement Study as well as recent Asian studies (namely the China Health and Retirement Longitudinal Study and the Korean Longitudinal Study of Aging). The authors conclude with a discussion of methodological challenges and avenues for future research, such as paying greater attention to grandfatherhood, greatgrandparenthood, or grandchildlessness.

Because multigenerational family relations appear to be becoming increasingly diverse in structure and function, other substantive issues that deserve further consideration include step-grandparenthood (e.g. Yahirun et al. 2018) as well as co-residential (or custodial) grandparenting. Whereas the latter is a quantitatively relevant and well-investigated phenomenon in the USA (e.g. Hayslip Jr et al. 2017), little is known yet about co-resident grandparents in Europe. The article by Glaser and colleagues (2018, in this issue) contributes to closing this gap by investigating trends in the prevalence of grandparents living with grandchildren in six European countries and the USA. Analysing census microdata for a period covering three to four decades from the 1980 s to the 2010s, the authors found that the proportion of three-generation households increased only in the USA and in Romania (but not-different from initial expectations-in the familistic societies of Greece, Portugal, and Spain). In all countries, however, co-resident grandparent households were characterised by socio-economic disadvantage.

Grandparenthood and taking an active role as a grandmother or grandfather, however, has sometimes also been shown to be advantageous for older people (e.g. in terms of better health outcomes). Arpino et al. (2018, in this issue) builds on this literature by investigating whether being a grandparent and providing grandchild care is associated with older Europeans' subjective well-being. Based on SHARE data for 20 countries, the authors found a generally positive association between grandparental involvement in childcare and subjective well-being (largely independent of education and gender). In those countries, however, where it is socially expected for grandparents to provide grandchild care, not taking on this activity appears to negatively affect elders' subjective well-being.

\footnotetext{
${ }^{1}$ All articles as well as the idea to present them jointly in this journal were inspired by the 2nd South Tyrol Workshop on Intergenerational Relationships held in Brixen-Bressanone (Italy) on 3-4 October 2016.
}

As Italy is clearly one of the countries in which grandparents constitute a fundamental resource for the provision of informal childcare, the Italian context deserves particular attention. Zamberletti et al. (2018, in this issue) provide a nuanced socio-demographic profile of older Italians providing different types of childcare. Their findings suggest that it is not only important to examine differences between intensive and occasional grandchild care across welfare states and family regimes (e.g. Bordone et al. 2017), but that exploration of this issue within a single-in this case familistic-societal context is also needed. For instance, even in societies like Italy's where divorce rates are comparatively low, there is growing concern that increases in divorce are challenging grandparents' ability to fulfil their traditional role. Post-divorce custodial and residential arrangements are thought to constitute a threat to the grandparent-grandchild relationship, especially along the paternal line. Albertini and Tosi (2018, in this issue) investigated the determinants of grandparenting after parental divorce in Italy, focusing on the determinants of non-resident parent-child meetings. Their results show that minor children who frequently meet with their non-resident divorced parent are more likely to receive grandparental childcare.

In sum, the contributions to this Special Section demonstrate the importance $(a)$ of taking a three-generational perspective, if we want to understand family functioning; (b) of considering a cross-nationally comparative perspective-without forgetting to take up-close pictures of specific societal contexts; $(c)$ of accounting for the (potential) complexity of family structures and of $(d)$ considering inequalities in different family configurations. Naturally, the scope to provide comprehensive answers to any of these aspects is limited, even if one is in the fortunate situation of having a Special Section on this issue that the Editors of the European Journal of Ageing have generously provided for us. We sincerely hope that the articles collected here will stimulate further research (in Europe and beyond), which will eventually allow us to get closer to answering at least some of the remaining gaps in our knowledge about grandparents-and to develop new questions for future research.

\section{References}

Albertini M, Tosi M (2018) Grandparenting after parental divorce: The association between non-resident parent-child meetings and grandparenting in Italy. Eur J Ageing. https://doi.org/10.1007/ s10433-018-0478-z

Arpino B, Bordone V, Balbo N (2018) Grandparenting, education and subjective well-being of older Europeans. Eur J Ageing. https:// doi.org/10.1007/s10433-018-0467-2

Bengtson V (2001) Beyond the nuclear family: the increasing importance of multigenerational bonds. J Marriage Fam 63:1-16 
Bordone V, Arpino B, Aassve A (2017) Patterns of grandparental child care across Europe: the role of the policy context and working mothers' need. Ageing Soc 37:845-873

Börsch-Supan A, Brandt M, Litwin H, Weber G (eds) (2013) Active ageing and solidarity between generations in Europe. De Gruyter, Berlin

Glaser K, Stuchbury R, Price D, Di Gessa G, Ribe E, Tinker A (2018) Trends in the prevalence of grandparents living with grandchild(ren) in selected European countries and the United States. Eur J Ageing. https://doi.org/10.1007/s10433-018-0474-3

Hank K, Erlinghagen M (2010) Volunteering in ‘old' Europe-patterns, potentials, limitations. J Appl Gerontol 29:3-20

Hank K, Cavrini G, Di Gessa G, Tomassini C (2018) What do we know about grandparents? Insights from current quantitative data and identification of future data needs. Eur J Ageing. https://doi. org/10.1007/s10433-018-0468-1

Hayslip Jr B, Fruhauf C A, Dolbin-MacNab ML (2017) Grandparents raising grandchildren: what have we learned over the past decade? The Gerontologist
Leopold T, Skopek J (2015) The demography of grandparenthood: an international profile. Soc Forces 94:801-832

Lumsdaine RL, Vermeer SJC (2015) Retirement timing of women and the role of care responsibilities for grandchildren. Demography 52:433-454

Margolis R (2016) The changing demography of grandparenthood. J Marriage Fam 78:610-622

Margolis R, Wright L (2017) Healthy Grandparenthood: how long is it and how is it changing? Demography 54:2079-2099

Yahirun JJ, Park SS, Seltzer JA (2018) Step-grandparenthood in the United States. J Gerontol: Soc Sci

Zamberletti J, Cavrini G, Tomassini C (2018) Grandparents providing childcare in Italy. Eur J Ageing. https://doi.org/10.1007/s1043 3-018-0479-y 